\title{
Preparation and Mechanism of a New Enhanced Flocculant Based on Bentonite for Drinking Water
}

\author{
Feng-shan Zhou, Jie Li, Lin Zhou, and Yang Liu \\ Beijing Key Laboratory of Materials Utilization of Nonmetallic Minerals and Solid Wastes, National Laboratory of Mineral Materials, \\ School of Materials Science and Technology, China University of Geosciences, Beijing 100083, China
}

Correspondence should be addressed to Feng-shan Zhou; zhoufs@cugb.edu.cn

Received 12 July 2014; Revised 29 October 2014; Accepted 14 November 2014

Academic Editor: Hanlie Hong

Copyright (c) 2015 Feng-shan Zhou et al. This is an open access article distributed under the Creative Commons Attribution License, which permits unrestricted use, distribution, and reproduction in any medium, provided the original work is properly cited.

Bentonite is characterized by the large specific surface, good adsorption, ion exchange ability, and nontoxicity. An enhanced bentonite base composite flocculant (BTA) can be prepared from treating the calcium base bentonite and compositing various functional additives. Bentonite was firstly treated by citric acid, then the talc and activated carbon turned to be acid part and simultaneously the part that was treated by sodium bicarbonate and calcium hydroxide turned to be alkaline part, and finally the acid bentonite part and alkaline bentonite part were mixed up with preground powder of polymeric chloride aluminium (PAC), cationic polyacrylamide (CPAM), ferrous sulfate, and aluminum sulfate, and after all of the processing flocculant BTA was obtained. The optimum preparation process of flocculant BTA has shown $29.5 \%$ acid bentonite part, $29.5 \%$ alkaline bentonite part, $15 \%$ PAC, $1 \%$ CPAM, 5\% ferrous sulfate, and 20\% aluminum sulfate. BTA was used to treat drinking water with high turbidity and metal ion in Karamay City, Xinjiang. The treated water was surely up to the drinking water standard of China in decolorization rate, deodorization rate, heavy metal ion removal rate, and so forth, and contents of residual aluminum ions and acrylamide monomer in drinking water were considerably decreased.

\section{Introduction}

China is facing water shortage and severe water pollution. In order to reduce the harm of water pollution, improve and protect environment, and achieve higher water quality, domestic as well as industrial water was often purified. Among various water treatment agents, flocculants have been found to be with wide application due to their satisfying purification performance, low cost, and convenience. Flocculants are the most widely used agents with the largest consumption in water treatment and mainly include inorganic flocculant, organic polymer flocculant, microbial flocculant, and composite flocculants [1].

In recent years, based on investigation of surface activity, ultrafine effect, chemical component, and crystal structure of natural minerals, minerals are found to have good environment attributes and natural minerals were applied in water pollution management due to their self-purification in various pollutants [2-6]. As flocculants, mineral materials have the advantage in wide varieties, abundant reserve, low cost, and little secondary pollution. The frequently used minerals include montmorillonite, sepiolite, zeolite, kieselguhr, and attapulgite [7-15].

$\mathrm{Si}^{4+}$ in $\mathrm{Si}-\mathrm{O}$ tetrahedron and $\mathrm{Al}^{3+}$ in $\mathrm{Al}-\mathrm{O}$ octahedron of bentonite could be replaced by low valence states of $\mathrm{Li}^{+}$, $\mathrm{Mg}^{2+}$, and $\mathrm{Fe}^{2+}$, thus making the unbalanced electrovalence of bentonite unit cell, so bentonite interlayer is negatively charged. In interlayer, the negatively charged surface will often balance with exchangeable hydrated cations which are unstable and also tend to exchange with other ions. Consequently, bentonite has good adsorption and ion exchange ability, cohesiveness, hydrophilicity, and large specific surface $[10,11,15]$, and, above all, it is nontoxic.

Bentonite was often used as adsorbent in water treatment mainly due to its good adsorption and ion exchange ability and this adsorption includes both exchange adsorption and physical absorption [12].

There were a lot of researches on bentonite being water treatment agent. For example, Liao and Wang used bentonite 
as adsorbent to prepare purifier to treat sewage of winery and the rate of deturbidity was reported as $37.6 \%$ at $5 \%$ purifier dosage [13]. Combining bentonite with flocculant PAC or PAM, Yuan et al. treated oily sewage and compared the oil removal performance of different kinds of bentonite and organic modified bentonite. They found that oil removal rate was as high as $90 \%$ at calcium base bentonite dosage of $2.5 \mathrm{~g} / \mathrm{L}$ and PAC dosage of $400 \mathrm{ppm}[14,15]$. Srinivasan [6] and many other researchers [16-18] made a detailed and comprehensive investigation on the applications of natural clay minerals including bentonite in removing biological, organic, and inorganic contaminants in drinking water.

\section{Materials and Methods}

2.1. Instruments and Materials. 101-1 Electric Blast Drying Oven (Tianjin Qin Shite Instrument Co., Ltd); ZDM-50 Vibration Mill (Tianjin Keqi Technology Co., Ltd); and SGE-2 Digital Turbidity Meter (Shanghai Yuefeng Instruments Co., Ltd.) were used.

All of the industrial produced samples in our work such as calcium bentonite (Ningcheng, Inner Mongolia), polyaluminum chloride (PAC) (Gongyi, Henan), Talc (Dandong, Liaoning), activated carbon (Gongyi, Henan), polyacrylamide (PAM), and cationic polyacrylamide (CPAM) (Xitao, Beijing) obtained from China chemical market. All of the chemical pure samples such as citric acid (chemically pure, CP), sodium bicarbonate $(\mathrm{CP})$, ferrous sulfate $(\mathrm{CP})$, aluminium sulfate $(\mathrm{CP})$, and calcium hydroxide (analytical reagent, $\mathrm{AR}$ ) were obtained from Beijing chemical reagent supply and marketing Co.

\subsection{Methods}

\subsubsection{Pretreatment of Raw Material}

Pretreatment. Calcium base bentonite activation adopts the thermal activation method. Calcium base bentonite was heated for $24 \mathrm{~h}$ at $300^{\circ} \mathrm{C}$ and then ground to $100-200$ mesh by vibrating mill for spare.

Pretreatment of the Additives. Additives including citric acid, talc, activated carbon, sodium bicarbonate, calcium hydroxide, ferrous sulfate, and aluminum sulfate were ground, respectively, to passing 200 mesh screen for spare.

Pretreatment of the Flocculants. PAC, PAM, and CPAM were ground, respectively, to passing 100 mesh screen for spare.

2.2.2. Preparation of Flocculant Base Powder. Acid powder A and basic powder $B$ were firstly prepared, respectively, and then powder $A$ and powder $B$ were mixed up in a proper ratio to form $\mathrm{AB}$ component. As diatomite with $\mathrm{pH}=7$ was used in evaluation tests to simulate suspension liquid, the optimized mass ratio of powder A and powder B was 1:1. After system optimization, the compositions and mass ratio of component $\mathrm{A}$ and component $\mathrm{B}$ were shown in Table 1.
TABLE 1: The compositions and the mass ratio of acid component $\mathrm{A}$ and basic component B.

\begin{tabular}{lccc}
\hline \multicolumn{2}{c}{ Acid component A } & \multicolumn{2}{c}{ Basic component B } \\
Raw materials & $\begin{array}{c}\text { Content } \\
(\mathrm{wt} \%)\end{array}$ & Raw materials & $\begin{array}{c}\text { Content } \\
(\mathrm{wt} \%)\end{array}$ \\
\hline Ca-bentonite & 80 & Ca-bentonite & 80 \\
Citric acid & 10 & Sodium bicarbonate & 10 \\
Talc & 9.5 & Calcium hydroxide & 10 \\
Activated carbon & 0.5 & & \\
\hline
\end{tabular}

\subsubsection{Preparation of Flocculant BTA}

(1) Weigh raw material referring to Table 1 and then after being extruded by extruder, dried and ground for 10 min to passing 100 mesh screen, powder $\mathrm{A}$ and powder B were obtained.

(2) Mix powder A and powder $B$ at the mass ratio of $1: 1$ and then powder $\mathrm{AB}$ was obtained.

(3) Weigh PAC, PAM, ferrous sulfate, and aluminum sulfate in a certain proportion and then mix them up with powder $\mathrm{AB}$; vibrating grind for $10 \mathrm{~min}$, the enhanced flocculant BTA was obtained.

2.2.4. Mechanism of Preparation of Flocculant BTA. The preferred composition of the present product was manufactured in two separately manufactured portions or subcomponents (acid First Portion A and alkaline Second Portion B) by extruding a calcium bentonite component that was not acidactivated, together with an acid and optionally an alkali, separately from the sodium bentonite component, to prevent the acid and alkali components from interacting or reacting with the sodium bentonite component of the composition, while the calcium bentonite-containing portion of the composition should be extruded to activate the calcium bentonite and bind any acid and alkali to the calcium bentonite, thereby preventing any acid and alkali from interacting with the sodium bentonite. It was not necessary to extrude the sodium bentonite containing portion of the composition.

All components of the composition may be extruded, so long as any acid and alkali components are maintained separately from the sodium bentonite during the extrusion process. Next, when extruded with calcium bentonite, the acid and alkali disperse more quickly in the waste water to prepare the waste water for later flocculation by the sodium bentonite. Dispersing the acid as early as possible, prior to dispersing the sodium bentonite, is important to break up the oil and grease emulsions. Dispersing the alkali as early as possible and prior to dispersing the sodium bentonite is important for precipitation of dissolved metals, so that the bentonite, later dispersed, can flocculate the oil, grease, and precipitated metals, together with the flocculating agent. Of all examples, various compositions were manufactured by extruding all composition components in two separate composition portions and then grinding the two extruded composition portions into a desired granular particle size distribution with other adding agents. 
The extruded calcium bentonite pellets, including bound acid and optionally alkali, were ground to a desired granular particle size distribution in the range of about $200 \mu \mathrm{m}$ to $1000 \mu \mathrm{m}$, and the ground granules from both portions of the composition were combined into a single composition, together with some other enhanced flocculating additives.

\section{Results and Discussion}

According to the composite principle, factors that could affect the performances of flocculant BTA mainly included the content of inorganic polymer flocculant PAC, type and content of precipitating aid, $\mathrm{pH}$ value of water in flocculation, and content of ferrous sulfate and aluminum sulfate. These four factors were investigated, respectively, and then compositions and their ratios in BTA system were determined.

\subsection{Influence of Inorganic Flocculant PAC on BTA Performan-} ces. Inorganic flocculant PAC with the largest consumption was the most widely used and has excellent absorption and bridging effect and charge neutralization performance. PAC used in the test also functions as flocculant and therefore investigating its influence rule on turbidity removal matters much.

As shown in Figure 1, flocculation effect of BTA was enhanced as a function of PAC content but the increase degree slows down. According to the data, the increase degree accelerated generally when PAC content was lower than $45 \%$ and rate of deturbidity reached $95.1 \%$ at PAC content of $40 \%$, while when PAC content was $50 \%$, rate of deturbidity only increased to $96.9 \%$. Consequently, taking cost into consideration, PAC content in BTA was determined as $40 \%$.

\subsection{Influence of Organic Precipitating Aid on BTA Perfor-} mances. All derivatives of polyacrylamide were excellent precipitating aid. The influences of anionic polyacrylamide (PAM) and cationic polyacrylamide (CPAM) on flocculation effect of BTA were investigated in tests, shown in Figure 2.

It was shown in Figure 2 that precipitating aid performance of cationic polyacrylamide (CPAM) significantly outperformed that of anionic polyacrylamide (PAM) in both rate of deturbidity and settling time. The performance and structure of bentonite indicate that its interlayer was negatively charged permanently. If the enhanced flocculant BTA contained bentonite, cationic polyacrylamide was more apt to adsorb and bridge with bentonite while anionic polyacrylamide will not react with bentonite obviously.

It was also found that only small amount of CPAM could promote the flocculation effect of BTA greatly and flocculation effect of BTA could be completely reflected. It was observed that the alum grains of enhanced flocculant BTA were larger than that of flocculant PAC, since the settling velocity of BTA was fast and it took only about $40 \mathrm{~s}$ for its floccules to settle completely while it took 2 to $3 \mathrm{~min}$ for PAC to settle completely. Referring to test results, flocculation precipitating aid adopted CPAM and its content accounts for $1 \%$ (mass fraction) of BTA system.

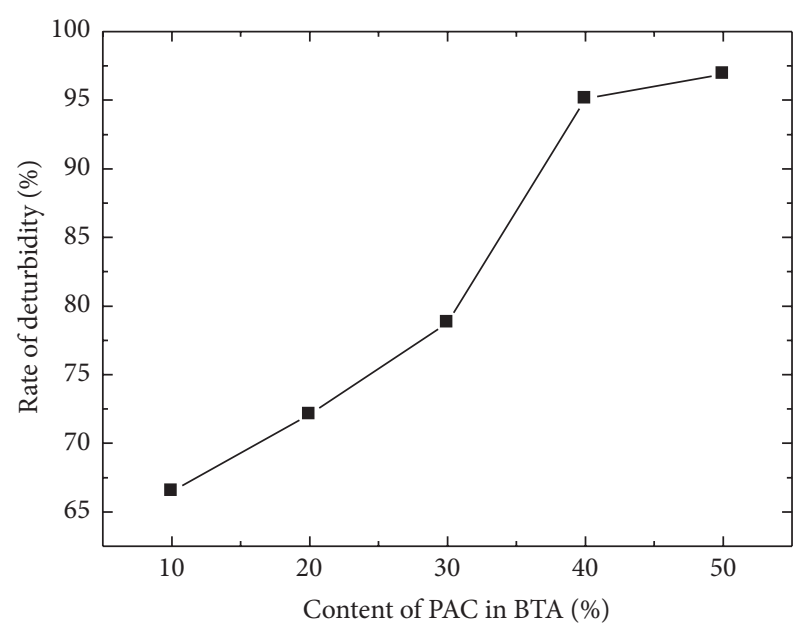

FIgURE 1: The effect of PAC in BAT on the rate of deturbidity.

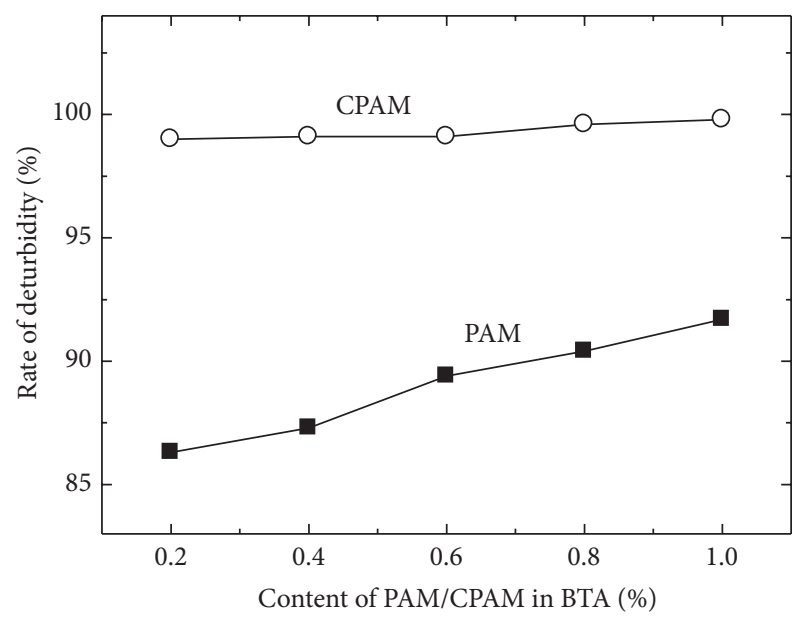

FIgUre 2: The effects of PAM/CPAM in BAT on the rate of deturbidity.

3.3. Influence of Flocculation Precipitating Aid on BTA Performance. Results showed that when the proportion of bentonite base powder, PAC, and CPAM in enhanced flocculant BTA system was $59 \%, 40 \%$, and $1 \%$, respectively, the flocculation effect could be as good as that of solid PAC and flocculating settling velocity is faster than that of solid PAC. However, as the dosage of enhanced flocculant was often large, thus costs in subsequent sludge treatment would increase and domestic flocculants were cheap, so it was necessary to control the costs of flocculants. Consequently, PAC content in the system should be reduced on condition that the flocculation effect was as good as the deturbidity effect of solid PAC and the settling velocity of sludge was faster than that of solid PAC. Meanwhile, ferrous sulfate and aluminum sulfate were considered to be added in the system as flocculation aid.

The flocculation effects of flocculation precipitating aids with PAC content of $10 \%, 15 \%, 20 \%$, and $30 \%$ were shown in Tables 2, 3, 4, and 5, respectively. By adjusting the proportion 
TABLE 2: The influence of additives on coagulation behaviors of BTA while PAC content was 10\% (200NTU diatomite suspension).

\begin{tabular}{lcccc}
\hline AB (\%) & $\begin{array}{c}\text { Aluminium } \\
\text { sulfate }(\%)\end{array}$ & $\begin{array}{c}\text { BTA } \\
(\mathrm{mg} / \mathrm{L})\end{array}$ & $\begin{array}{c}\text { Rate of } \\
\text { deturbidity } \\
(\%)\end{array}$ & $\begin{array}{c}\text { Settling } \\
\text { time }(\mathrm{s})\end{array}$ \\
\hline 5 & 25 & 100 & 99.2 & 20 \\
10 & 20 & 100 & 99.1 & 20 \\
15 & 15 & 100 & 95.3 & 60 \\
20 & 10 & 100 & 95.8 & 60 \\
25 & 5 & 100 & 95.1 & 60 \\
- & - & PAC (100) & 98.1 & 60 \\
\hline
\end{tabular}

TABLE 3: The influence of additives on coagulation behaviors of BTA while PAC content was 15\% (200NTU diatomite suspension).

\begin{tabular}{lcccc}
\hline $\begin{array}{l}\text { Ferrous } \\
\text { sulfate } \\
(\%)\end{array}$ & $\begin{array}{c}\text { Aluminium } \\
\text { sulfate }(\%)\end{array}$ & $\begin{array}{c}\text { BTA } \\
(\mathrm{mg} / \mathrm{L})\end{array}$ & $\begin{array}{c}\text { Rate of } \\
\text { deturbidity } \\
(\%)\end{array}$ & $\begin{array}{c}\text { Settling } \\
\text { time }(\mathrm{s})\end{array}$ \\
\hline 0 & 25 & 100 & 98.8 & 20 \\
5 & 20 & 100 & 98.7 & 20 \\
10 & 15 & 100 & 98.7 & 60 \\
15 & 10 & 100 & 98.3 & 60 \\
20 & 5 & 100 & 98.4 & 60 \\
25 & 0 & 100 & 98.0 & 60 \\
- & - & PAC (100) & 98.5 & 60 \\
- & - & PAC (50) & 97.7 & 90 \\
\hline
\end{tabular}

TABLE 4: The influence of additives on coagulation behaviors of BTA with $20 \%$ PAC (200NTU diatomite suspension).

\begin{tabular}{lcccc}
\hline $\begin{array}{l}\text { Ferrous } \\
\text { sulfate } \\
(\%)\end{array}$ & $\begin{array}{c}\text { Aluminium } \\
\text { sulfate }(\%)\end{array}$ & $\begin{array}{c}\text { BTA } \\
(\mathrm{mg} / \mathrm{L})\end{array}$ & $\begin{array}{c}\text { Rate of } \\
\text { deturbidity } \\
(\%)\end{array}$ & $\begin{array}{c}\text { Settling } \\
\text { time }(\mathrm{s})\end{array}$ \\
\hline 0 & 20 & 100 & 98.0 & 40 \\
5 & 15 & 100 & 98.2 & 40 \\
10 & 10 & 100 & 98.1 & 40 \\
15 & 5 & 100 & 97.7 & 40 \\
20 & 0 & 100 & 97.7 & 50 \\
- & - & PAC (100) & 98.4 & 60 \\
- & - & PAC (50) & 97.6 & 90 \\
\hline
\end{tabular}

TABLE 5: The influence of additives on coagulation behaviors of BTA with $30 \%$ PAC (200NTU diatomite suspension).

\begin{tabular}{lcccc}
\hline $\begin{array}{l}\text { Ferrous } \\
\text { sulfate } \\
(\%)\end{array}$ & $\begin{array}{c}\text { Aluminium } \\
\text { sulfate }(\%)\end{array}$ & $\begin{array}{c}\text { BTA } \\
(\mathrm{mg} / \mathrm{L})\end{array}$ & $\begin{array}{c}\text { Rate of } \\
\text { deturbidity } \\
(\%)\end{array}$ & $\begin{array}{c}\text { Settling } \\
\text { time }(\mathrm{s})\end{array}$ \\
\hline 0 & 10 & 100 & 98.9 & 30 \\
5 & 5 & 100 & 98.7 & 30 \\
10 & 0 & 100 & 98.7 & 30 \\
- & - & PAC (100) & 98.5 & 90 \\
- & - & PAC (50) & 98.2 & 120 \\
\hline
\end{tabular}

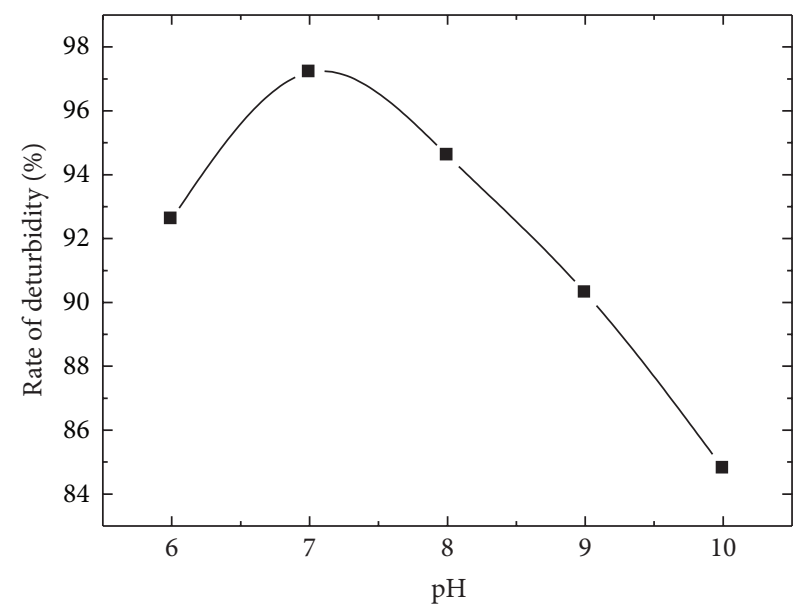

FIGURE 3: The influence of $\mathrm{pH}$ on coagulation behaviors of BTA.

of ferrous sulfate and aluminum sulfate and comparing with PAC, the optimal blending ratio of BTA was determined.

Results showed that generally rate of deturbidity changes little when PAC content ranges from $10 \%$ to $30 \%$, but it could be observed in tests that floccules of BTA were small at PAC content of $10 \%$. Consequently, the content of PAC in the system was finally determined as $15 \%$.

According to the influence of ferrous sulfate and aluminum sulfate, flocculation effect generally got better as a function of aluminum sulfate content. However, as ferrous sulfate could increase the compactness of floccules and decrease the function of COD, it was an indispensable part of the system. Combining turbidity removal performance and economic effect, the optimized compositions of enhanced flocculant BTA were shown in Table 6.

3.4. Influence of $p H$ on BTA Performance. It could be known from flocculating mechanism that flocculation was caused by hydrolysis of flocculant in water. BTA contained some flocculants, for example, PAC, and the flocculation effect was directly affected by $\mathrm{pH}$ of water, and therefore the suitable environment of enhanced flocculant BTA should be determined. Diatomite suspension with $\mathrm{pH}$ of 6 to 10 was prepared, respectively, to simulate sewage and then the suitable environment could be found by observing the change of flocculation effect, as shown in Figure 3. The best flocculation effect of BTA was observed at $\mathrm{pH}$ 7, which agreed with the suitable environment of PAC.

3.5. Application of Flocculant BTA in Treating Moderately Polluted Drinking Water. Karamay City, located in Junggar Basin of northwestern Xinjiang, is an industrial city that mainly depends on oil industry. According to random inspection results, only $53.4 \%$ of drinking water in average met the quality standard and that percentage in rain season and dry season was $45.6 \%$ and $61.9 \%$, respectively. It was reported that domestic drinking water of citizens came in sequence from natural raw water, processed water from drinking water treatment plant, tip water of water supply network, and secondary 
TABLE 6: The optimized compositions of BTA.

\begin{tabular}{lcccccc}
\hline Component & Acid part A & Basic part B & PAC & CPAM & Ferrous sulfate & Aluminium sulfate \\
\hline Content (\%) & 29.5 & 29.5 & 15 & 1 & 5 & 20 \\
\hline
\end{tabular}

TABLE 7: The treatment effect for Xinjiang Karamay City drinking water with enhanced flocculant BTA.

\begin{tabular}{|c|c|c|c|c|}
\hline Number & Testing items & $\begin{array}{l}\text { China National Standard } \\
\text { (China GB 5749-2006) }\end{array}$ & $\begin{array}{l}\text { Testing results } \\
(\mathrm{SN} . \mathrm{G} 2013024) \\
\end{array}$ & Unit \\
\hline 1 & Chromaticity & $\leq 15$ & $<5$ & Degree \\
\hline 2 & Turbidity & $\leq 1$ or $\leq 3$ & $<0.5$ & NTU \\
\hline 3 & Odor and taste & No foreign order and taste & No & \\
\hline 4 & Visible matter & No & No & \\
\hline 5 & $\mathrm{pH}$ & $6.5-8.5$ & 7.92 & \\
\hline 6 & Total hardness (as $\mathrm{CaCO}_{3}$ ) & $\leq 450$ & 189 & $\mathrm{mg} / \mathrm{L}$ \\
\hline 7 & Iron & $\leq 0.3$ & $<0.005$ & $\mathrm{mg} / \mathrm{L}$ \\
\hline 8 & Manganese & $\leq 0.1$ & $<0.022$ & $\mathrm{mg} / \mathrm{L}$ \\
\hline 9 & Copper & $\leq 1.0$ & $<0.0015$ & $\mathrm{mg} / \mathrm{L}$ \\
\hline 10 & Zinc & $\leq 1.0$ & $<0.0015$ & $\mathrm{mg} / \mathrm{L}$ \\
\hline 11 & Cadmium & $\leq 0.005$ & $<2.0 \times 10^{-6}$ & $\mathrm{mg} / \mathrm{L}$ \\
\hline 12 & Lead & $\leq 0.01$ & $<5.0 \times 10^{-5}$ & $\mathrm{mg} / \mathrm{L}$ \\
\hline 13 & Volatile phenol (as phenol) & $\leq 0.002$ & $<0.002$ & $\mathrm{mg} / \mathrm{L}$ \\
\hline 14 & Composite anionic detergent & $\leq 0.3$ & $<0.05$ & $\mathrm{mg} / \mathrm{L}$ \\
\hline 15 & Sulfate & $\leq 250$ & 93.82 & $\mathrm{mg} / \mathrm{L}$ \\
\hline 16 & Chloride & $\leq 250$ & 109.38 & $\mathrm{mg} / \mathrm{L}$ \\
\hline 17 & Total dissolved solids & $\leq 1000$ & 304 & $\mathrm{mg} / \mathrm{L}$ \\
\hline 18 & Fluoride & $\leq 1.0$ & 0.38 & $\mathrm{mg} / \mathrm{L}$ \\
\hline 19 & Cyanide & $\leq 0.05$ & $<0.002$ & $\mathrm{mg} / \mathrm{L}$ \\
\hline 20 & Arsenic & $\leq 0.01$ & $<9.0 \times 10^{-4}$ & $\mathrm{mg} / \mathrm{L}$ \\
\hline 21 & Selenium & $\leq 0.01$ & $<9.0 \times 10^{-4}$ & $\mathrm{mg} / \mathrm{L}$ \\
\hline 22 & Mercury & $\leq 0.001$ & $<9.0 \times 10^{-5}$ & $\mathrm{mg} / \mathrm{L}$ \\
\hline 23 & Chromium (hexavalent) & $\leq 0.05$ & $<0.004$ & $\mathrm{mg} / \mathrm{L}$ \\
\hline 24 & Nitrate (as nitrogen) & $\leq 10$ & 0.45 & $\mathrm{mg} / \mathrm{L}$ \\
\hline 25 & Trichloromethane & $\leq 0.06$ & $<2.0 \times 10^{-4}$ & $\mathrm{mg} / \mathrm{L}$ \\
\hline 26 & Tetrachloromethane & $\leq 0.002$ & $<1.0 \times 10^{-4}$ & $\mathrm{mg} / \mathrm{L}$ \\
\hline 27 & Bacterial colony number & $\leq 100$ & 30 & $\mathrm{CFU} / \mathrm{mL}$ \\
\hline 28 & Total $\alpha$ radioactivity & $\leq 0.5$ & $<0.016$ & $\mathrm{~Bq} / \mathrm{L}$ \\
\hline 29 & Total $\beta$ radioactivity & $\leq 1$ & 0.038 & $\mathrm{~Bq} / \mathrm{L}$ \\
\hline 30 & Oxygen consumption (as $\mathrm{O}_{2}$ ) & $\leq 3$ & 1.75 & $\mathrm{mg} / \mathrm{L}$ \\
\hline 31 & Aluminum & $\leq 0.2$ & 0.092 & $\mathrm{mg} / \mathrm{L}$ \\
\hline
\end{tabular}

water supply in high-rise housing. Processed water referred to water being treated in drinking water treatment plant, and tip water of supply network meant water branched from main water supply line, while secondary water supply meant providing domestic drinking water for residents indirectly by secondary water supply facilities, for example, impounding reservoir and its attaching pipeline, valve, pumping unit, and pressure tank. As raw water quality was unchangeable, the drinking water quality cannot meet the standard all the year round.

Tests on using enhanced flocculant BTA to treat the source water of No. 2 Water Purification Plant of Xinjiang
Oilfield Company were carried out in 2013. The processed water quality was tested by Water Quality Supervision and Inspection Station, Xinjiang Petroleum Administration Bureau. As shown in Table 7, the treated water was surely up to the drinking water standard of China in decolorization and deodorization rate, removal rate of heavy metal ion, and so forth, and contents of residual aluminum ions and acrylamide monomer in drinking water were considerably decreased, thus reflecting the powerful adsorption property of bentonite as natural mineral material and showing a great prospect of the enhanced bentonite base flocculant in drinking water treatment. 
TABLE 8: The costing evaluation for flocculant BTA based on the price of raw materials purchased from Beijing chemical market in 2013.

\begin{tabular}{lccc}
\hline Raw material & $\begin{array}{c}\text { Content } \\
(\mathrm{wt} \%)\end{array}$ & $\begin{array}{c}\text { Price } \\
(\mathrm{RMB} ¥ / \mathrm{t})\end{array}$ & $\begin{array}{c}\text { Cost } \\
(\mathrm{RMB} ¥ / \mathrm{t})\end{array}$ \\
\hline PAC & 15.0 & 2000 & 300 \\
Ca-bentonite & 47.2 & 500 & 236 \\
Talc & 2.95 & 600 & 17 \\
Calcium hydroxide & 2.95 & 700 & 20 \\
Citric acid & 2.95 & 5000 & 147 \\
Sodium bicarbonate & 2.95 & 1500 & 44 \\
Ferrous sulfate & 5.0 & 400 & 20 \\
Aluminum sulfate & 20.0 & 800 & 160 \\
CPAM & 1.0 & 25000 & 250 \\
\hline Total cost of raw materials (RMB¥/t) & \multicolumn{2}{c}{1194} \\
Estimated total produced cost (RMB¥/t) & \multicolumn{2}{c}{200} \\
Total cost of flocculant BTA (RMB¥/t) & \multicolumn{2}{c}{1400} \\
\hline
\end{tabular}

3.6. Applied Cost of Flocculant BTA. The main raw materials of the new enhanced flocculant BTA used natural clay mineral bentonite, which is abundant in our country, combined with simple production process to get the excellent coagulation behavior, so BTA had a good economic feasibility. Table 8 listed the raw materials of BTA and their market prices. Due to the low cost and simple production process of BTA, the solid medicament was convenient for transportation and sewage rate significantly faster than conventional PAC, especially suitable for the modern small sewage treatment needs. Therefore the new enhanced flocculant BTA would have good applications in the future.

Using the new enhanced flocculant BTA to treat the source water of No. 2 Water Purification Plant of Xinjiang Karamay City in 2013, the original treatment price was 0.09 $0.12 \mathrm{RMB} ¥$ per ton drinking water which included about PAC 0.10RMB¥ coupled with the CPAM 0.01RMB¥. If we used PAC only, the treated water quality could not meet the drinking water standard. When the BTA flocculant was used singly to treat the source water of above water plant, the processed cost was only 0.03 0.06RMB¥ per ton drinking water, and the treated water quality was better.

\subsection{Mechanism of Bentonite Based Flocculant Enhancing Flocculation}

3.7.1. PAC, CPAM, and Their Interactions. PAC and CPAM really are typical and effective flocculants widely used in water treatment sites. Their excellent coagulation properties had been well studied and widely accepted.

The main coagulating function of PAC was its high charge, which made it more effective at destabilizing and removing suspended materials than other aluminium salts such as aluminium sulfate and aluminium chloride, in which the aluminium structure results in a lower net charge than aluminium chlorohydrate. Aluminium chlorohydrate was the best representative described as an inorganic polymer and as

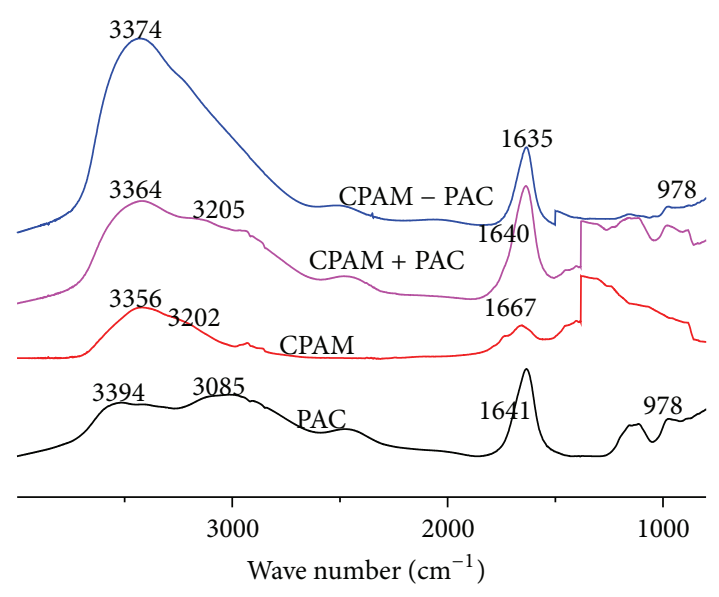

FIGURE 4: The FTIR of PAC after enhanced reaction of modification with cationic PAM.

such was difficult to structurally characterise. However, techniques such as gel permeation chromatography, X-ray crystallography, and ${ }^{27} \mathrm{Al}-\mathrm{NMR}$ have been used in researches and had been shown such that the material was based on $\mathrm{Al}_{13}$ units with a Keggin ion structure and that this base unit then underwent complex transformations to form larger polyaluminium complexes $[18,19]$.

The primary role of CPAM was characterized by its macromolecular chains, because the macromolecular chains had a variety of lively groups, which will capture many nucleophilic substances by hydrogen bonds in the macromolecular chains especially for negatively charged colloid particles. CPAM was mainly used for turbidity, bleaching, adsorption, adhesion, and other functions in water purification process [18-20].

Figure 4 was the infrared structure changes of PAC modified with PAM (formed PAC-PAM composite) before and after enhanced modified reaction, which included physical superposition infrared spectra of PAC + PAM with OMINIC 5.0 software. It was shown that $\mathrm{Al}$ interacted with $-\mathrm{O}-$ on $-\mathrm{CONH}_{2}$, weakening the effect of PAM molecular chain $\mathrm{C}=\mathrm{O}$. The characteristic absorption peak of PAM in 1561 $1667 \mathrm{~cm}^{-1}$, that is, amide I belt and amide II belt, decreased significantly in the spectra of PAC-PAM, and the absorption peak of PAM in $3202 \mathrm{~cm}^{-1}$ has already disappeared in PACPAM too. We can also see that the IR spectra of PAM + PAC and the IR spectra of PAM, PAC were significantly different, which was enough to prove that the PAM used as coagulant aid was through the chemical reaction between the PAM and PAC to play a role rather than just physical blend. It revealed that the essence of PAM composite synergistic PAC was indeed to generate a greater molecular weight of the new polymer (because of PAM, PAC flocculation characteristics compared with PAC had greatly increased), and that was not the traditional flocculation theory, which was considered such that PAM only had a physical bridging role, and the enlargement alum floc flowers formed just through mechanical netting $[21,22]$. 
3.7.2. Bentonite, Flocculating Additives, and Their Interactions. Enhanced bentonite base flocculant BTA contained five kinds of key material with different function, that is, clay mineral to quickly form flocculation core, inorganic polymer flocculant to supply electrical neutralization, organic polymer to aid precipitating functioning, and acid and alkaline bentonite components to help adjusting $\mathrm{pH}$ of water. The flocculation performance of this composite flocculant would not be affected by clay minerals. On the contrary, clay minerals would be improved flocculation and accelerate settling velocity. This composite flocculant was equipped with excellent flocculation and turbidity removal performance and fast settling, and it overcame the disadvantage of PAC in difficult settling as a result of its light floccules, so it was suitable for rapid treatment (i.e., enhanced flocculation) of sewage and drinking water of various turbidities $[23,24]$.

Based on heterogeneous nucleation theory and differential flocculation model, bentonite, clay mineral with excellent hydrophilicity, was selected as base in tests and mineral base composite flocculant BTA was prepared by compositing conventional inorganic polymer flocculant PAC, organic polymer precipitating aid PAM, and other flocculation aids. Composite flocculant BTA contained many flocculation cores and could produce flocculation core efficiently in the presence of water. Meanwhile, bentonite could adsorb other micromolecules and colloid pollutants effectively due to its good adsorption capacity [25, 26]. Enhanced flocculant BTA made full use of the heterogeneous nucleation and adsorption capacity of clay minerals, electrical neutralization of inorganic polymer flocculant, and adsorption and bridging capacity of organic polymer. Therefore, BTA, as a new functional composite flocculant, would indeed enhance flocculation performance and promoted flocculation efficiency.

\section{Conclusions}

Based on heterogeneous nucleation theory and differential flocculation model, factors affecting flocculation performance were analyzed comprehensively. Calcium base bentonite being treated as the main base, a new functional bentonite base composite flocculant BTA aiming at enhancing flocculation rapidly, was prepared by compositing conventional inorganic polymer flocculant, organic polymer precipitating aid, and other flocculation aids. Evaluation results of flocculation performance showed that turbidity removal performance of BTA was as good as that of PAC while settling time of its floccules was one time faster than that of PAC's floccules. When BTA was used to treat drinking water with high turbidity and metal ion content, the treated water was surely up to the drinking water standard of China in discoloration and deodorization rate, heavy metal ion removal rate, and so forth and contents of residual aluminum ions and acrylamide monomer in drinking water were considerably decreased, thus reflecting the powerful adsorption property of bentonite as environmental mineral material. Due to its cheap raw materials, easily available material source, and simple preparation process, the special enhanced bentonite base flocculant showed a great prospect in drinking water treatment.

\section{Conflict of Interests}

The authors declare that there is no conflict of interests regarding the publication of this paper.

\section{Acknowledgment}

This research was supported by National High Technology Research and Development Program of China (863 Program 2012AA06A109).

\section{References}

[1] F.-S. Zhou, S.-H. Wang, J.-Y. Li, and J.-G. Wu, "Progress in researches of polysilicate-containing composite inorganic polymer flocculants," Oilfield Chemistry, vol. 19, no. 4, pp. 391394, 2002.

[2] S. Triantafyllou, E. Christodoulou, and P. Neou-Syngouna, "Removal of nickel and cobalt from aqueous solutions by $\mathrm{Na}$ activated bentonite," Clays and Clay Minerals, vol. 47, no. 5, pp. 567-572, 1999.

[3] S.-H. Lin and R.-S. Juang, "Heavy metal removal from water by sorption using surfactant-modified montmorillonite," Journal of Hazardous Materials, vol. 92, no. 3, pp. 315-326, 2002.

[4] K. G. Bhattacharyya and S. S. Gupta, "Adsorption of a few heavy metals on natural and modified kaolinite and montmorillonite: a review," Advances in Colloid and Interface Science, vol. 140, no. 2, pp. 114-131, 2008.

[5] C. Cooper and R. Burch, "Mesoporous materials for water treatment processes," Water Research, vol. 33, no. 18, pp. 36893694, 1999.

[6] R. Srinivasan, "Advances in application of natural clay and its composites in removal of biological, organic, and inorganic contaminants from drinking water," Advances in Materials Science and Engineering, vol. 2011, Article ID 872531, 17 pages, 2011.

[7] Z. P. Ren and Z. Z. Yang, "The environmental protection function of minerals and its application perspective," Conservation and Utilization of Mineral Resources, vol. 2001, no. 3, pp. 44-48, 2001.

[8] X. F. Xie and J. G. Wang, "Application of clay mineral materials in water treatment," Metallic Ore Dressing Abroad, vol. 2001, no. 1, pp. 22-25, 2001.

[9] X. Q. Cui, X. J. Lv, and G. H. Zhou, "The property and application of bentonite," China Non-Metallic Mining Industry Herald, vol. 2000, no. 2, pp. 6-9, 2000.

[10] X. Q. Zeng and W. P. Liu, "Advance in synthesis of inorganoorgano-montmorillonites and their utilization in water treatment," Techniques and Equipment for Environmental Pollution Control, vol. 2, no. 2, pp. 9-10, 2001.

[11] X. J. Peng, J. Z. Yuan, and M. L. Cao, "Application of modified bentonite in wastewater treatment," China Non-Metallic Mining Industry Herald, vol. 2005, no. 5, pp. 40-41, 2005.

[12] F. C. Yi and J. Yang, "The properties and preparation of water purifying agent with bentonite," Multipurpose Utilization of Mineral Resources, vol. 1999, supplement 1, pp. 27-28, 1999.

[13] X. F. Liao and Z. L. Wang, "Adsorption and flocculation of bentonite to emulsified oil wastewater," Environmental Pollution \& Control, vol. 21, supplement 1, pp. 78-79, 1999.

[14] Z. X. Yuan, H. L. Zheng, and X. W. Shu, "Advancement of coagulation science and technology," Journal of Chongqing 
University (Natural Science Edition), vol. 24, no. 2, pp. 143-147, 2001.

[15] C. Cao, F. Zhou, Z. Zhang et al., "Preparation and evaluation of high yield sodium-modified calcium base bentonite," Earth Science Frontiers, vol. 20, no. 5, pp. 220-226, 2013.

[16] D. Thakre, S. Rayalu, R. Kawade, S. Meshram, J. Subrt, and N. Labhsetwar, "Magnesium incorporated bentonite clay for defluoridation of drinking water," Journal of Hazardous Materials, vol. 180, no. 1-3, pp. 122-130, 2010.

[17] S. P. Kamble, P. Dixit, S. S. Rayalu, and N. K. Labhsetwar, "Defluoridation of drinking water using chemically modified bentonite clay," Desalination, vol. 249, no. 2, pp. 687-693, 2009.

[18] B. J. Xu, Contemporary Water Supply and Wastewater Treatment Principle, Higher Education Press, Beijing, China, 1992.

[19] H. X. Tang and Z. K. Luan, "The differences of behavior and mechanism between pre-polymeric inorganic flocculants and traditional coagulants," in Chemical Water and Wastewater Treatment IV, H. H. Hahn, Ed., vol. 9, Springer, Berlin, Germany, 1996.

[20] H. X. Tang, Z. K. Luan, D. S. Wang, and B. Y. Gao, "Composite inorganic polymer flocculants," in Chemical Water and Wastewater Treatment $V, \mathrm{H}$. H. Hahn, E. Hoffman, and H. Odegaard, Eds., pp. 25-34, Springer, Berlin, Germany, 1998.

[21] F.-S. Zhou, S.-H. Wang, J.-Z. Su et al., "Structural characteristics of infrared spectra for polyaluminum chloride in enhanced reactions of modification," Spectroscopy and Spectral Analysis, vol. 24, no. 5, pp. 532-535, 2004.

[22] F.-S. Zhou, S.-H. Wang, J.-Z. Su et al., "The infrared spectra and characteristics of PMC-a multicore inorganic polymer flocculant," Fine Chemicals, vol. 20, no. 10, pp. 615-620, 2003.

[23] J.-Q. Jiang and C. G. Kim, "Comparison of algal removal by coagulation with clays and Al-based coagulants," Separation Science and Technology, vol. 43, no. 7, pp. 1677-1686, 2008.

[24] C. S. Choi and T. I. Yun, "Rapid coagulation-flocculation and sedimentation type waste water treatment method," United States Patent 6447686, 2002.

[25] H. H. Murray, "Traditional and new applications for kaolin, smectite, and palygorskite: a general overview," Applied Clay Science, vol. 17, no. 5-6, pp. 207-221, 2000.

[26] G. J. Churchman, "Formation of complexes between bentonite and different cationic polyelectrolytes and their use as sorbents for non-ionic and anionic pollutants," Applied Clay Science, vol. 21, no. 3-4, pp. 177-189, 2002. 

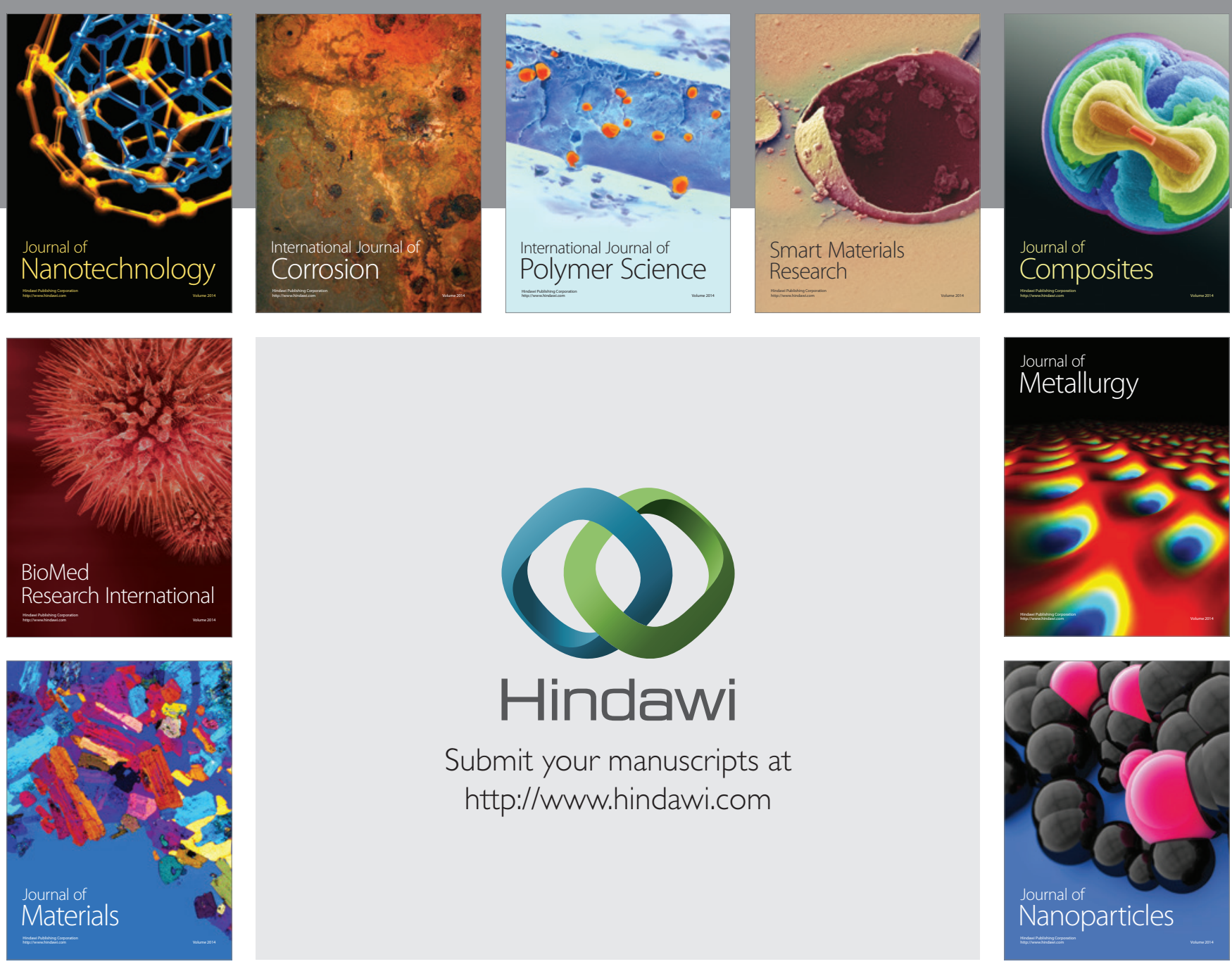

Submit your manuscripts at http://www.hindawi.com
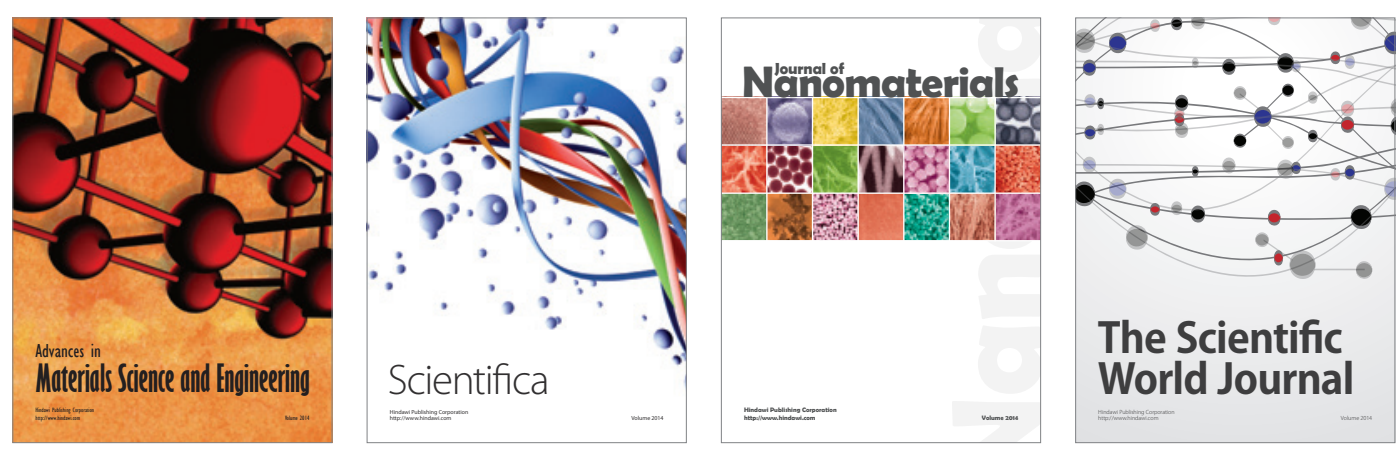

\section{The Scientific World Journal}
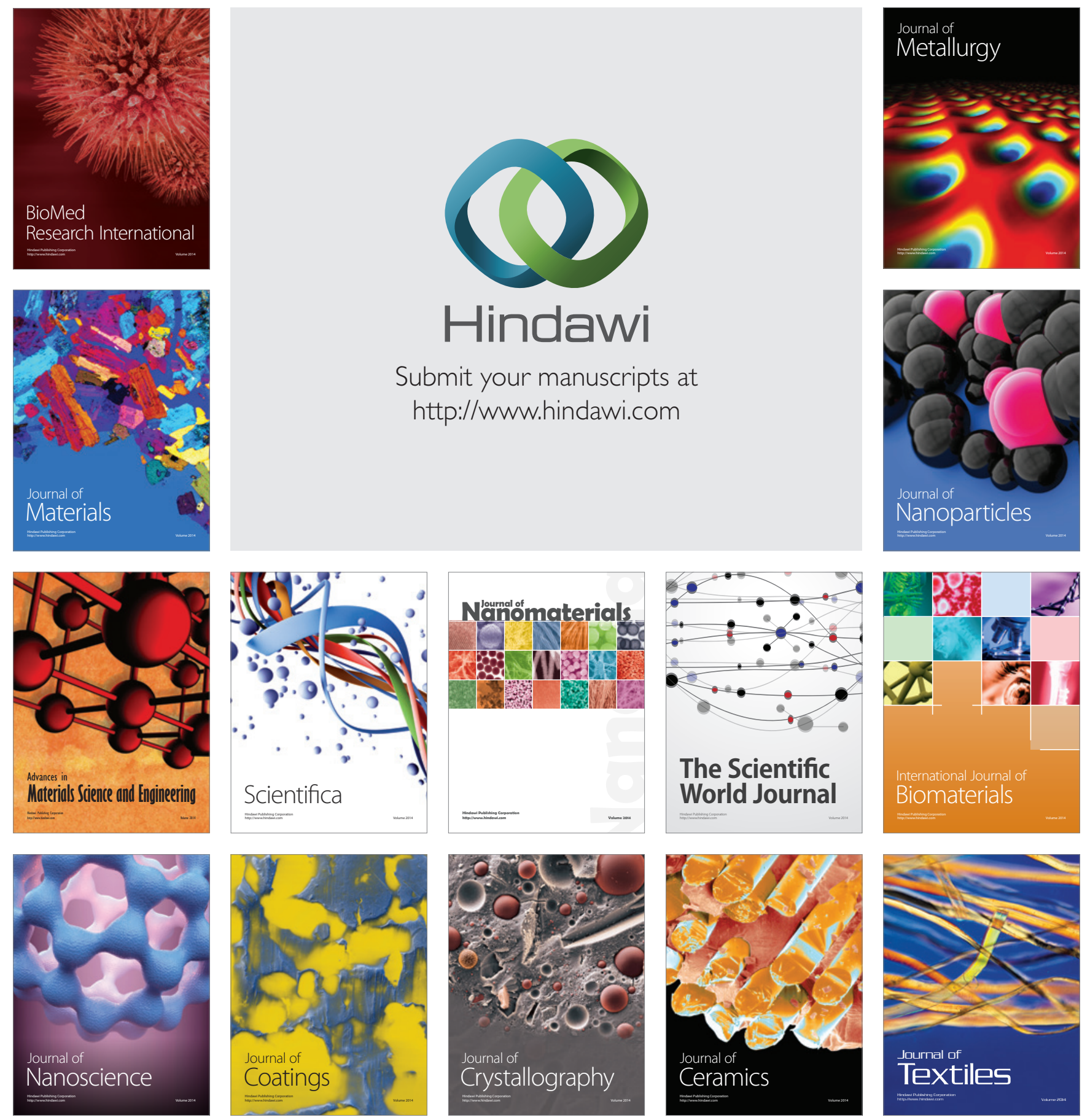